\title{
MINERAIS: FATORES QUE INTERFEREM NA BIODISPONIBILIDADE DE MACRO E MICROMINERAIS PARA FÊMEAS RUMINANTES DURANTE O PERÍODO DE GESTAÇÃO
}

\author{
REZENDE, Fernanda Valim ${ }^{1}$ \\ DIAS E SILVA, Nhayandra Christina ${ }^{1}$ \\ FLORENTINO, Ligiane Aparecida ${ }^{1}$ \\ REZENDE, Adauton Vilela de ${ }^{1}$
}

Recebido em: 2019.06.26

Aprovado em: 2019.11.22

ISSUE DOI: $10.3738 / 21751463.3660$

\begin{abstract}
RESUMO: Os minerais são classificados em macro e microminerais em função da quantidade diária exigida pelo animal. Os macrominerais são aqueles exigidos em maiores quantidades, como o cálcio, fósforo, sódio, cloro, potássio, magnésio e enxofre, enquanto que os microminerais são aqueles exigidos em menores quantidades, como o cobalto, cobre, iodo, ferro, manganês, selênio e zinco. A alimentação exerce influência sobre a reprodução e os nutrientes apresentam mecanismos específicos de atuação sobre a eficiência produtiva, principalmente durante a gestação, que qualquer desequilíbrio, pode comprometer a produção da matriz e da cria ao longo de sua vida. O objetivo deste estudo foi abordar a importância dos minerais, suas funções metabólicas, bem como expor os fatores que interferem na biodisponibilidade destes durante a gestação. Vários fatores interferem na utilização dos minerais na gestação os quais podemos destacar a quantidade de energia e proteína ingerida, estado nutricional e fatores genéticos, e principalmente, às interações que ocorrem entre minerais versus minerais e minerais versus vitaminas. Durante um estado de desbalanço mineral no organismo da fêmea na gestação, a placenta diminui sua capacidade de compensar o fornecimento adequado de nutrientes para o feto, o que limita sua capacidade de crescimento e resulta em crias com má formação, susceptíveis a doenças, além de acarretar em aborto em casos de subnutrição ou supernutrição. Sendo assim, os minerais exercem uma grande importância na nutrição e conhecer os fatores que interferem na sua biodisponibilidade na gestação é crucial para o desenvolvimento da matriz e do feto.
\end{abstract}

Palavras- chave: Deficiência. Feto. Interação. Prenhez. Suplementação Mineral

\section{MINERALS: FACTORS THAT INTERFERE IN THE BIOAVAILABILITY OF MACRO AND MICROMINERALS FOR RUMINANT FEMALES DURING THE GESTATION PERIOD}

\begin{abstract}
SUMMARY: The minerals are classified in macro and microminerals according to the daily amount required by the animal. Macrominerals are those required in larger amounts, such as calcium, phosphorus, sodium, chlorine, potassium, magnesium and sulfur, while microminerals are also used as trace elements, are those required in smaller quantities, such as cobalt, copper, iodone, iron, manganese, selenium and zinc. Feeding influences reproduction and nutrients present specific mechanisms of performance on productive efficiency, especially during gestation, that any imbalance, however small, may compromise the health and production of the mother and fetus through its production life. The objective of this study was to expose the importance of minerals, highlighting their metabolic functions, as well as exposing the factors that interfere in the bioavailability of these by ruminant females during gestation. Several factors interfere in the use of minerals by gestating, which can highlight the amount of energy and protein ingested, nutritional status and genetic factors, and especially the interactions that occur between minerals versus minerals and minerals versus vitamins. During a state of mineral imbalance in the female's body during pregnancy, the placenta decreases its ability to compensate for the adequate supply of nutrients to the fetus, which limits its ability to grow and results in malformed, susceptible abortion in cases of malnutrition or intense mineral malnutrition. Thus, minerals present a major role in nutrition and the factors that interfere with their bioavailability during pregnancy are crucial for the development of the mother and the fetus.
\end{abstract}

Keywords: Deficiency. Fetus. Interaction. Mineral Supplementation. Pregnancy

${ }^{1}$ Programa de Pós Graduação em Ciência Animal - Universidade José do Rosário Vellano

Nucleus Animalium, v.11, n.2, nov. 2019 


\section{INTRODUÇÃO}

Os minerais são constituintes inorgânicos e fundamentais para o bom funcionamento dos processos metabólicos do organismo animal, e encontra-se em quantidades variadas em razão do tecido ou órgão, sendo definidos como essenciais quando alguma função vital exercida pelo mineral no organismo é comprovada (SILVA et al., 2017). Segundo o NRC (2007), os macrominerais, como são designados, são elementos minerais que possuem demandas mais elevadas dentre os demais, como o cálcio, fósforo, magnésio, sódio, potássio, cloro e enxofre. Em contrapartida, os microminerais ou elementos traços (como são designados em alguns estudos), são àqueles demandados em menor quantidade pelo organismo, como é o caso do ferro, iodo, zinco, cobre, cobalto, manganês e selênio. Ainda, segundo esse mesmo comitê, assim como INRA (1981), AFRC (1993) e CSIRO (2007), outros minerais têm sido indicados como possíveis elementos essenciais, como é o caso do molibdênio, cádmio, flúor, silício, cromo, vanádio, níquel, arsênio e estanho.

No Brasil, a suplementação de minerais ainda é fundamental na produção animal, principalmente para animais que vivem em condições de pastejo, uma vez que já é comprovado que nossos solos são deficientes em vários minerais essenciais (TOKARNIA et al., 2000). Neste sentido, para que os programas de suplementação mineral sejam eficientes, é importante considerar tanto a composição mineral da dieta a ser fornecida, como também a necessidade diária do animal em cada fase de vida.

A gestação destaca-se por ser uma das fases mais críticas da vida produtiva dos ruminantes, principalmente no terço final da gestação, onde ocorre o maior crescimento fetal, onde é exigido uma grande demanda de nutrientes. Sendo assim, o suprimento da exigência de minerais de acordo com a fase gestacional que a fêmea está, é imprescindível para que todas as alterações metabólicas ocorram de forma adequada, sem comprometimento do adequado desenvolvimento da mãe e do feto (COSTA et al., 2003).

Atualmente, sabe-se que a simples presença de um mineral na dieta não garante sua utilização pelo organismo, e por isso, o metabolismo mineral não pode ser visto apenas de uma forma isolada, e sim como um todo. Vários fatores fisiológicos e nutricionais podem interferir na absorção, no transporte e no armazenamento, com subsequente aumento da suscetibilidade à deficiência ou toxidade de um ou mais minerais (COUZI et al., 1993).

Diante do exposto e da importância que os minerais exercem na nutrição animal, e principalmente, pelo fato do conhecimento sobre a biodisponibilidade mineral ainda ser limitado, o objetivo deste é estudo foi abordar a importância dos minerais na dieta de fêmeas ruminantes ao 
longo da gestação, bem como os fatores que interferem na biodisponibilidade de macro e microminerais durante este período.

\section{MINERAIS NA DIETA DE FÊMEAS RUMINANTES EM GESTAÇÃO}

Os minerais são os constituintes inorgânicos do corpo animal e estão sempre em pequenas proporções nos tecidos corporais, exceto ósseo, quando comprados à gorduras e proteínas. De acordo com McDowell (1992), podem corresponder até 4\% do peso vivo do animal, sendo que cerca de 3,5\% dos $4 \%$ são compreendidos pelos macrominerais, principais cátions e ânions do corpo animal, como cálcio $(\mathrm{Ca})$, fósforo $(\mathrm{P})$, potássio $(\mathrm{K})$, sódio $(\mathrm{Na})$, cloro $(\mathrm{Cl})$, enxofre $(\mathrm{S})$ e magnésio $(\mathrm{Mg})$, de forma que o $\mathrm{Ca}$ representa em torno de $46 \%$ desse total e o $\mathrm{P}$ aproximadamente $29 \%$. Já os microminerais, como o ferro $(\mathrm{Fe})$, iodo $(\mathrm{I})$, zinco $(\mathrm{Zn})$, cobre $(\mathrm{Cu})$, cobalto (Co), manganês (Mn) e selênio (Se) contribuem com cerca de 0,3\% desse total.

Segundo Underwood e Suttle (1999), cerca de 50 minerais são encontrados no organismo animal, mas até o presente momento apenas somente 14 deles são considerados essenciais. Assim, a importância de cada um deles não depende somente da quantidade exigida, mas também da função desempenhada nos processos metabólicos, devendo estar presente na alimentação em quantidades suficientes para suprir as funções fisiológicas, estruturais, catalíticas e reguladoras. É importante ressaltar que essas funções

não são exclusivas de um único mineral, podendo cada um exercer várias outras funções, com ação antagônica ou sinérgica.

A fase de gestação é importante e crucial na vida produtiva da matriz não somente pelas diversas mudanças fisiológicas que ocorrem no corpo, mas sim por ser responsável por todo o desenvolvimento do feto, que vai refletir diretamente em toda a vida produtiva e reprodutiva da cria (GRUNNERT e BIRGEL, 1982). Sendo assim, a nutrição mineral adequada da fêmea gestante é fundamental para seu desenvolvimento como matriz e para transferir todos os nutrientes necessários para o perfeito crescimento e evolução do feto (HAFEZ e HAFEZ, 2004). A maior parte da transferência dos nutrientes do corpo materno para o feto se dá por meio de processo ativo (que envolve gasto de energia), o que pode ficar comprometida caso a dieta não forneça todos os nutrientes exigidos (STULC, 1997; McDONALD et al., 2001). Segundo Coelho e Silva et al. (1995), deficiências no aporte nutricional neste período, levam a redução do peso ao nascimento entre 10 e $25 \%$, dependendo do grau de restrição.

\subsection{Macrominerais}


O Cálcio $(\mathrm{Ca})$ é o mineral mais abundante no corpo e está presente principalmente nos ossos. Atua também na coagulação sanguínea, permeabilidade celular, contração muscular, transmissão dos impulsos nervosos, regulação cardíaca, secreção de certos hormônios e ativador enzimático (PEDREIRA; BERCHIELLI, 2006).

O fósforo $(\mathrm{P})$ e o magnésio $(\mathrm{Mg})$ também estão presentes em sua maior parte, nos ossos, e geralmente é estudado em conjunto com o $\mathrm{Ca}$, devido à interdependência nutricional, metabólica e semelhança nas funções (LANA, 1992). O P atua no catabolismo de carboidratos por meio da adenosina trifosfato (ATP), na permeabilidade da célula como fosfolipídios, na transmissão de impulsos nervosos por ser um componente da bainha de mielina (AMMERMAN; GOODRICH, 1983; LARVOR, 1983), e possui inter-relação com o cálcio, por promover a formação da matriz óssea, bem como a sua mineralização (SUTTLE, 2010). Enquanto que o Mg, além da função estrutural, atua como cofator enzimático e está envolvido principalmente na captura de energia (KOVACKS, 2012; SUTTLE, 2010).

Durante as semanas que antecedem o parto e o início da lactação, ocorre uma grande demanda da quantidade de minerais, principalmente de $\mathrm{Ca}, \mathrm{P}$ e $\mathrm{Mg}$, devido aos processos de calcificação fetal e preparação para a lactação. Dessa forma, principalmente nas últimas semanas de gestação, a ingestão de pastagem é insuficiente para suprir a demanda de minerais, e se não houver a suplementação mineral, possivelmente ocorrerá uma mobilização óssea intensa, o que resultará em desordem metabólica e comprometimento da matriz e do feto (BRAITHWAITE, 1983).

É importante ressaltar que a susceptibilidade dos animais à deficiência de $\mathrm{Ca}, \mathrm{P}$ e $\mathrm{Mg}$, acentua-se principalmente com o avanço da idade, devido à uma dificuldade progressiva em mobilizar esses minerais do esqueleto e também à redução da capacidade de absorção intestinal desses elementos (UNDERWOOD, 1981).

O sódio $(\mathrm{Na})$ e o potássio $(\mathrm{K})$ atuam em conjunto, na manutenção da pressão osmótica, balanço ácido-base, balanço cátion-aniônico do fluido corporal, contração muscular e transmissão nervosa. Como ocorre a interação entre o $\mathrm{Na}$ e $\mathrm{K}$ entre os fluidos corporais, o fornecimento e a qualidade da água são essenciais no metabolismo desses elementos no organismo (MARTIN, 2005).

Diferentemente dos estoques de $\mathrm{Ca}, \mathrm{P}$ e $\mathrm{Mg}$ nos ossos, não há reservas de $\mathrm{Na}$ e $\mathrm{K}$ além daquele encontrado no músculo e células nervosas, por isso, a suplementação desses minerais deve ser fornecida, evitando assim, deficiências e consequentemente, disfunções celulares.

Sinais de deficiência de Na são evidentes na gestação quando os animais passam a lamber superfícies, apresentam fraqueza, perda de peso e diminuição da produção de leite. Enquanto que 
os sinais de depleção de $\mathrm{K}$ incluem anorexia, crescimento retardado, irritabilidade, paralisia e tetania (HAFEZ; DYER, 1969; UNDERWOOD, 1970).

Embora não encontre relatos sobre a deficiência de cloro $(\mathrm{Cl})$ durante a gestação, é um mineral que é componente do suco gástrico na formação do ácido clorídrico e que atua basicamente na degradação das proteínas no abomaso, além de ser mediador no balanço ácido/básico do sangue e ter função de ativação das amilases. Além disso, também exerce a função de regulador da pressão osmótica, regulação do equilíbrio acidobásico e controle do equilíbrio hídrico (PETTY, 1995).

O enxofre (S) é encontrado amplamente nos alimentos como um constituinte da proteína e está relacionado com o balanço catiônico-aniônico das dietas, podendo influenciar diretamente nos sistemas ácido-base sanguíneos (LEITE, 2003). Sua exigência pelos ruminantes no período de gestação se deve principalmente ao suprimento adequado e maximização da síntese microbiana no rúmen (PEDREIRA; BERCHIELLI, 2006).

\subsection{Microminerais}

O ferro (Fe) está diretamente associado ao organismo animal nas reações que envolvem o transporte e utilização de oxigênio, principalmente como componente de proteína, como hemoglobina e mioglobina. A absorção gastrointestinal do Fe ocorre principalmente no duodeno e a principal rota de excreção de Fe são as fezes e urina, existindo perdas adicionais no suor, pelos e cascos (McDOWELL, 2003).

Segundo o NRC (2001), o conteúdo de ferro (Fe) nas plantas forrageiras pode variar de 70 a 500mg de Fe/Kg. No Brasil, os solos tropicais são considerados ácidos e com uma razoável concentração de $\mathrm{Fe}$, o que faz com que a suplementação desse mineral em relação a outros microminerais seja menos importante (PEDREIRA; BERCHIELLI, 2006).

Quanto ao iodo (I), sua principal função fisiológica é como componente dos hormônios tireoidianos: tirosina (T4) e triiodotironina (T3). Os hormônios tireoidianos influenciam todos os órgãos no estágio de desenvolvimento, crescimento e maturação. Esses hormônios ainda estão relacionados à maturação epitelial, função reprodutiva, desenvolvimento ósseo e na gênese do embrião e do feto (GLINOER, 2001).

Em fêmeas, durante o período de gestação, o iodo é transportado prontamente da placenta para o feto e a função da tireoide se inicia cedo na formação do feto (GRAHAM, 1991). Dessa forma, a suplementação de I é primordial para o funcionamento adequado das glândulas da 
tireoide da matriz para assegurar que o desenvolvimento neurológico do feto progrida normalmente ao longo da gestação (GLINOER, 2001).

O zinco (Zn) é um microelemento, que no organismo animal, está envolvido na síntese de vitamina $\mathrm{A}$, transporte de $\mathrm{CO}_{2}$, metabolismo dos carboidratos, ácidos nucléicos e na síntese de proteínas (DAVIES, 1980). Sua absorção ocorre principalmente no duodeno, contudo, essa absorção pode sofrer flutuações devido à presença de algumas enzimas e outros elementos como cálcio, cobre, selênio e cádmio (DAVIES, 1980). Aproximadamente $85 \%$ do total de Zn do corpo encontram-se dentro das células, com $40 \%$ encontrado nos núcleos celulares. Uma quantidade variável pode residir nas vesículas e pode servir como reserva celular (OUTTEN; O’HALLORAN, 2001). Apgar et al. (1993) mantiveram ovelhas sem suplementação de Zn durante toda a gestação, e observaram que as fêmeas apresentaram parto laborioso, retenção de placenta e toxemia da gestação, concluindo que a suplementação de $\mathrm{Zn}$ deve ser fornecida às fêmeas em todo período de gestação, a fim de evitar problemas durante e no pós-parto.

O cobre $(\mathrm{Cu})$ desempenha importantes funções no organismo por participar como componente de diversas enzimas como citocromo-oxidase, lisil-oxidase, elastina, ceruloplasmina, tirosinase, superóxido-dismutase, entre outras. Para ovinos, é provavelmente o mineral que mais exige cuidado na suplementação, visto que essa espécie é extremamente susceptível à toxicidade por este microelemento. Já para os bovinos, a suplementação pode variar entre 50 a 100 ppm, dependendo da raça e do nível de ingestão de alimento. Ao contrário, os ovinos podem desenvolver quadros de toxicidade com concentrações menores do que $10 \mathrm{ppm}$ na dieta (CHURCH; POND, 1998).

Grandes mudanças no metabolismo de $\mathrm{Cu}$ ocorrem durante a gestação. Segundo Mills e Davies (1979), toda essa mudança é destinada à conservação de $\mathrm{Cu}$, de forma a aumentar a absorção e prevenção de perdas por vias de excreção, a fim de atender a alta demanda do feto durante a fase gestacional. É importante salientar que o $\mathrm{Cu}$ se acumula no feto a uma taxa exponencial, com um acréscimo diário até o final da gestação.

O cobalto (Co) é um micromineral importante na dieta dos ruminantes, visto que que faz parte do centro ativo da molécula de vitamina $B_{12}$ (ORTOLANI, 2002) e participa do metabolismo do ácido propiônico. Os ruminantes são os animais que mais necessitam de cobalto, onde o elemento é requerido e usado pela microbiota ruminal para converter o cobalto em vitamina $B_{12}$ e seus análogos (VAN SOEST, 1994). Os microrganismos ruminais são capazes de sintetizar essa vitamina, mas para isso, necessitam que o Co esteja presente na dieta. Diferentemente dos outros complexos de vitaminas $\mathrm{B}$, a vitamina $\mathrm{B}_{12}$ é sintetizada quase exclusivamente por bactérias e, portanto, está presente somente em alimentos que foram fermentados por bactérias ou são derivados de animais que obtém esta vitamina a partir do 
próprio trato gastrointestinal (COMBS, 1998). Durante a gestação, a deficiência de Co apresenta como principal sinal clínico a falta de apetite, o que resulta em menor ingestão de alimento, perda peso e diminuição da produção. Outra consequência indireta da carência de Co é a anemia e desordens metabólicas que ocorrem no fígado, principal órgão de maior estoque de vitamina $\mathrm{B}_{12}$ (Mc DOWELL, 1992).

O manganês $(\mathrm{Mn})$ é um mineral importante para os sistemas biológicos e age como ativador enzimático (LEACH e HARRIS, 1997) e formação da cartilagem, tornando-o essencial no crescimento epifisário, o que afeta diretamente o crescimento longitudinal do osso (LEACH e MUENSTER, 1962). É amplamente encontrado nos volumosos, estando presente numa quantidade muito acima das exigências dos ruminantes, porém, em alguns grãos, como o milho, seu conteúdo é baixo. Na gestação, sua deficiência está associada à problemas reprodutivos, como depressão ou retardamento do cio e baixa taxa de concepção, e má formação dos ossos da cria (HIGNETT, 1941; WILSON, 1996).

O Selênio (Se) é um micromineral essencialmente ligado à fertilidade e a prevenção de várias doenças reprodutivas (SUTTLE, 2010). Está presente nos tecidos do corpo e caracteriza-se por uma versátil capacidade de oxirredução, sendo tal característica fundamental para sua atuação no centro ativo da enzima glutationa-peroxidase, responsável pela eliminação de peróxidos (ORTOLANI, 2002).

A deficiência de Se durante a gestação está relacionada à desordens reprodutivas como manifestação de estros silenciosos, fracos e irregulares, baixa taxa de concepção, maior incidência de cistos ovarianos, retenção de placenta, infertilidade e abortos (OLSON, 1996).

\section{FATORES QUE INTERFEREM NA BIODISPONIBILIDADE DOS MINERAIS DURANTE A GESTAÇÃO}

Os minerais participam de uma série de mecanismos fisiológicos e bioquímicos, e estão largamente distribuídos pelo organismo, sendo que cada elemento possui uma ou várias funções no metabolismo que estão interligadas. Por isso, raramente eles podem ser admitidos como elementos isolados com independência e funções autossuficientes, pois podem sofrer influência de outros nutrientes em reações de sinergismo e antagonismo (GUINAN et al., 2005).

Segundo Moreira (2008), um mineral é considerado essencial quando estiver presente em concentração constante nos tecidos, com pouca variação de um animal para outro. Quando o mineral estiver deficiente, ele irá resultar em anormalidades estruturais ou fisiológicas. Contudo, se o animal for suplementado, os sintomas de deficiência deverão ser revertidos e as 
anormalidades serão acompanhadas por alterações bioquímicas especificas que cessam os sintomas da deficiência.

Ao partir do princípio que a simples presença do mineral na dieta não garante a sua utilização pelo organismo, têm-se buscado informações sobre a biodisponibilidade de minerais, que é definida como a proporção do mineral ingerido que é realmente disponível e que tem o potencial para suprir a demanda fisiológica do animal (SOUTHGATE et al., 1989).

Vários são os fatores que interferem na biodisponibilidade de minerais para os ruminantes, principalmente quando se trata de fêmeas em fase de gestação, onde a exigência nutricional é alta e todo o metabolismo é alterado para suprir a demanda do feto e da mãe (MILLER et al., 1993). Esses fatores consistem em uma sequência de eventos que podem interferir nas medidas de biodisponibilidade de minerais e que podem ser trabalhados de uma forma positiva para conseguir um melhor aproveitamento também de outros nutrientes, como proteínas, vitaminas e energia (HALLBERG et al., 1997).

\subsection{Quantidade ingerida de energia e proteína}

A ingestão de uma dieta balanceada consiste em fornecer todos os nutrientes e energia necessária para o organismo da fêmea gestante manter sua homeostase e suprir toda sua demanda metabólica. Sendo assim, o organismo da fêmea gestante, em teoria, deveria absorver mais um mineral específico quando suas reservas estão diminuídas e absorver menos quando suas reservas estão em condições adequadas ou em excesso. Contudo, a falta ou o excesso de um nutriente e energia pode interferir no aproveitamento os minerais, como é o caso da restrição de proteína e energia da dieta (COZZOLINO, 1997).

Estudos realizados por Sykes e Field (1972) e Braithwaite (1978) relatam que a restrição de energia e proteína na dieta afetou o metabolismo de macrominerais como $\mathrm{Ca}, \mathrm{P}$ e $\mathrm{Mg}$ em ovelhas, fazendo com que ocorresse um aumento de mobilização óssea devido a problemas gerados na absorção intestinal ou na deposição na matriz óssea. Quanto ao efeito da restrição de energia e proteina sobre a biodisponibilidade de microminerais, não há trabalhos que retratam esse tema.

\subsection{Estado nutricional e fatores genéticos}

A complexidade de se conhecer o estado nutricional da fêmea gestante é um fator de erro na determinação da biodisponibilidade de um mineral. Alguns estudos costumam avaliar previamente a capacidade de absorção de uma dose de mineral considerada de referência, para 
então determinar as diferenças entre os animais selecionados para uma avaliação (HALLBERG, 1980). Esta análise também tem sido realizada para outros minerais, verificando-se a eficiência da absorção de um elemento presente num alimento teste, comparada com uma dose de referência padrão. Assim, o resultado será a razão entre os dois (FAIRWEATHER-TAIT, 1996). É importante ressaltar que doenças e medicamentos, também podem interagir com minerais, na maioria das vezes diminuindo sua biodisponibilidade (COZZALINO, 1997).

Alguns fatores genéticos também são responsáveis por alterações na absorção de minerais. Como por exemplo, podemos citar, animais portadores de hemocromatose, onde ocorre aumento de absorção do ferro e acrodermatite enteropática, que é uma desordem genética que leva à deficiência de zinco (AGGETT, 1989).

\subsection{Interações minerais versus minerais}

Segundo Georgieviskii et al. (1982), os minerais interagem entre si com ação sinérgica ou antagonista. De acordo com a Embrapa (2001), os minerais sinérgicos possuem reciprocidade com a sua absorção no trato digestivo e exerce funções metabólicas no tecido ou na célula semelhantes, conforme o nível de absorção deste, que irá determinar suas proporções na dieta como, por exemplo, o cálcio com o fósforo; sódio com o cloro; e zinco e cobalto, entre outros. Ainda, há a interação indireta dos minerais com função estrutural, tendo como exemplo o cálcio e o fósforo na formação da hidroxiapatita no osso; e o cobre e o ferro na formação da hemoglobina.

O micromineral selênio é fundamental para o metabolismo do iodo, pois para transformar a tiroxina (T4) em triiodotironina (T3) há necessidade da enzima deiodinase, que é dependente de selênio e, portanto, é considerada uma interação indireta. Em fêmeas gestantes com deficiência de iodo e selênio, esses dois elementos devem ser suplementados concomitantemente, uma vez que a suplementação somente com selênio poderia ser danosa, pois resultaria numa maior produção de T3, a partir do T4 residual, que promoveria uma inibição da liberação de TSH, piorando o quadro de hipotiroidismo (LEVANDER e WHANGER, 1996).

Por outro lado, o antagonismo é determinado como o resultado gerado por um elemento sobre o outro no organismo, havendo conflito para as ligações metabólicas com as substâncias na corrente sanguínea, como por exemplo, o ferro com o zinco e cobre nas transferrinas plasmáticas.

Alguns metais pesados, como o cádmio e o mercúrio, podem se complexar com minerais essenciais como zinco e selênio no trato gastrointestinal, e desta forma serem excretados. Este aspecto é importante devido a diminuição da toxicidade, porém, a biodisponibilidade dos elementos essenciais é diminuída e pode ocasionar deficiências destes minerais, quando associados com uma baixa ingestão destes elementos. Também tem-se observado que com a 
deficiência de cálcio, ferro, zinco e cobre na dieta ocorre maior absorção de chumbo (COZZOLINO, 1997).

\subsection{Interações Vitaminas versus Minerais}

O desempenho reprodutivo das fêmeas pode ser também influenciado pelo balanço vitamínico e mineral, mesmo que de forma indireta. Todos os minerais e vitaminas tem algum tipo de relação com as funções reprodutivas, como por exemplo, a deficiência de $\mathrm{P}$, que tem efeito adverso sobre a conversão do caroteno em vitamina A, resultando na carência deste nutriente (SANTOS, 1998).

Tem sido observada uma correlação direta entre retinol sérico e níveis de hemoglobina. Os estudos sugerem que a deficiência de vitamina A prejudica a mobilização de Fe das reservas e também a produção de células vermelhas, porém tem pouca influência na absorção de Fe (LYNCH, 1997).

Já o zinco, é amplamente conhecido que a proteína ligadora do retinol (RBP), responsável pelo transporte da vitamina A do fígado para os tecidos alvos é dependente de zinco. Portanto, um sinal clínico da deficiência do zinco é a cegueira noturna provocada pela dificuldade no transporte da vitamina A (YUYAMA e COZZOLINO, 1995).

O selênio por sua vez, tem relação com a glutationa peroxidase (GSH Px), enzima dependente do micromineral selênio, que age na redução de peróxidos orgânicos, incluindo peróxidos de ácidos graxos livres e outros lipídeos. A estreita relação entre selênio e vitamina E tem base bioquímica, visto que a Vitamina $\mathrm{E}$ age minimizando o dano na membrana provocado pelos radicais livres. Assim, o selênio, por meio da glutationa peroxidase (GSH Px), age prevenindo o acúmulo de peróxido $(\mathrm{HOOH})$, que é fonte de radicais livres. Os radicais hidroxila podem causar danos às membranas das células, bem como a outros componentes celulares. Dessa forma, a necessidade de vitamina E é diminuída na presença de selênio (BRODY, 1994).

\section{CONSIDERAÇÕES FINAIS}

Os minerais exercem uma grande importância na nutrição e na produção de ruminantes, principalmente durante a gestação, visto que desempenham funções diversas a deficiência, podendo resultar em grandes perdas econômicas. $O$ entendimento da necessidade de suplementação de macro e microminerais para os ruminantes, em especial, para as fêmeas gestantes é decisivo para maior eficiência reprodutiva e produtiva. 
Estudos sobre a biodisponibilidade de minerais infelizmente ainda são muito escassos, entretanto, conhecer os fatores que podem interferir na biodisponibilidade dos minerais são cruciais para que se possa ter uma definição real, precisa e acurada da quantidade de minerais disponível para absorção, utilização metabólica e suprimento das exigências nutricionais durante a gestação.

\section{REFERÊNCIAS}

AGRICULTURAL AND FOOD RESEARCH COUNCIL (GREAT BRITAIN). TECHNICAL COMMITTEE ON RESPONSES TO NUTRIENTS. Energy and protein requirements of ruminants: an advisory manual. CAB international, 1993.

AGGETT, P. J. Severe zinc deficiency. In: Zinc in human biology. Springer, London. p. 259279, 1989.

AMMERMAN, C. B.; GOODRICH, R. D. Advances in Mineral Nutrition in Ruminants. Journal of Animal Science. Albany, v.57, p.519-533, 1983.

APGAR, J,; EVERETT, G. A.; FITZGERATD, J. A. Dietary Zinc Deprivation Affects Parturition and Outcome of Pregnancy in the Ewe. Nutrition Research. v. 13, p. 319- 330, 1993.

BRAITHWAITE, G. D. The effect of dietary protein intake on calcium metabolism of the pregnant ewes. Bristish Journal nutrition, v. 40, p. 505, 1978.

BRAITHWAITE, G. D. Calcium and phosphorus requirements of the ewe during pregnancy and lactation. British Journal Nutrition. v. 50, p.711-722, 1983.

BRODY, T. Nutritional biochemistry. [s.1.] : Academic Press, 1994. 660p.

COELHO DA SILVA, J. F. Exigências de macroelementos inorgânicos para bovinos: o sistema ARC/AFRC e a experiência no Brasil. Simpósio internacional sobre exigências nutricionais de ruminantes, v. 1, p. 467-504, 1995.

COMBS, G. F. The Vitamins. Fundamental Aspects in Nutrition and Health. 2nd ed. Academic Press, San Diego, CA.1998.

COSTA, R. G.; RESENDE, K. T.; RODRIGUES, M. T. Exigências de Minerais para Cabras durante a Gestação: Na, K, Mg, S, Fe e Zn. Revista Brasileira de Zootecnia, v. 32, n. 2, p. 431436, 2003.

COUZY, F. et al. Nutritional implications of the interactions between minerals. Progress in food \& nutrition science, v. 17, n. 1, p. 65-87, 1993.

COZZOLINO, S. M. F. Biodisponibilidade de Minerais. Revista Nutrição PUCCAMP. 10 (2): p. $87-98,1997$

CHURCH, D.C.; POND, W. G. Basic Animal Nutrition and Feeding. Published by John Wiley and Sons, New York. p. 196-199, ed. 3, 1998. 
CSIRO. Standing Committee on Agriculture. Ruminants Subcomittee Feeding standards for Australian Livestock. In: Ruminants. CSIRO Publications, East Melbourne, Australia. 2007.

DAVIES, N. T. Studies on the absorption of zinc by rat intestine. British Journal of Nutrition v.43, p. 189-203, 1980.

EMBRAPA. Centro Nacional de Pesquisa de Gado de Corte. A escolha dos animais para confinamento. 2001.

FAIRWEATHER-TAIT, S. J. Bioavailability of dietary minerals. Biochemical Society Transactions Colchester, v.24, n.3, p.775-780, 1996.

GEORGIEVSKII, V. I. The biological function and metabolism in the body. In:

GEORGIEVSKII, V. I.; ANNENKOV, B. N.; SAMOKHIN, V. I. Mineral nutrition of animals: studies in the agricultural an food sciences. London: Butterworths, p. 1- 269, 1982.

GLINOER, Daniel. Pregnancy and iodine. Thyroid, v. 11, n. 5, p. 471-481, 2001.

GRAHAM, T.W. Trace element deficiencies in cattle. The Veterinary Clinics of North America, Food Animal Practice, v.7, n.1, p.153-215, 1991.

GRUNERT, E.; BIRGEL, E. H. Fisiologia da prenhez. Obstetricia Veterinária. Porto Alegre: Sulina, ed. 3, p. 27-60, 1982.

GUINAN, M. et al. The effect of timing of mineral supplementation of the ewe diet in late pregnancy on immunoglobulin G absorption by the lamb. Animal Science, New York, v. 80, p. 193-200, 2005.

HAFEZ, E.S. E.; HAFEZ, B. Reprodução Animal. Tradução: original Renato Campanarut Barnabé - Barueri, SP. $7^{\mathrm{a}}$ ed, 2004, 513p.

HALLBERG, L. Food iron absorption. In: COOK, J.D. (ed). Methods in hematology: iron. New York : Churchill and Livingstone, p.116-193, 1980.

HALLBERG, L.; HULTEN, L.; GRAMATROVSKI, E. Iron absorption from the whole diet in men: how effective is the regulation of iron absorption? American Journal of Clinical Nutrition, Bethesda, v.66, p.347-356, 1997.

HIGNETT, S. L. Some aspects of bovine sterility. Veterinary Record, v. 53, p. 21, 1941.

INRA - INSTITUTO NATIONAL DE LA RECHERCHE AGRONOMIQUE. Alimentacion de los ruminants. Jarrige, R. Ed. Madrid, Mundi-Prensa. 697p., 1981.

KOVACS, C. S. Fetal mineral homeostasis. In: Pediatric Bone. Academic Press, p. 247-275, 2012.

LANA, R. P.et al. Composição corporal e do ganho de peso e exigências de energia, proteína e macroelementos minerais ( $\mathrm{Ca}, \mathrm{P}, \mathrm{Mg}, \mathrm{Na}$ e $\mathrm{K}$ ), de novilhos de cinco grupos raciais. 3. Conteúdo corporal e do ganho de peso e exigências de macroelementos minerais. Revista Brasileira de Zootecnia, v.21, n.2, p.538-549, 1992. 
LARVOR, P. The pools of cellular nutrients. In: RIIS, P.M. Dynamic biochemistry of animal production. Amsterdam: Elsevier, p.281-318, 1983.

LEACH JR, R. M.; MUENSTER, A.-M. Studies on the role of manganese in bone formation: I. Effect upon the mucopolysaccharide content of chick bone. The Journal of nutrition, v. 78, n. 1, p. 51-56, 1962.

LEACH, R. M.; HARRIS, J. L. Trace Element Metabolism in Animals. (Eds) W. G. Hoekstra, J. W. Suttie, H. E. Ganther, W. Mertz, p. 51-59. University Park Press: Baltimore, 1997.

LEITE, L.C.; ANDRIGUETTO, J. L., et al. Diferentes balanços catiônicos-aniônicos da dieta de vacas da raça Holandesa. Revista Brasileira de Zootecnia. v. 32, n. 5, Viçosa Set/Oct. 2003.

LEVANDER, O. A.; WHANGER, P. D. Deliberations and evaluations of the approaches, endpoints and paradigms for selenion and iodine dietary recommendations. Journal of Nutrition, Bethesda, v.126, p.2427S-2434S, 1996.

LYNCH, S.R. Interaction of iron with other nutrients. Nutrition Reviews, New York, v.55, n.4, p.102-110, 1997.

MARTIN, D. W. Structure-function relationships in the Na+, K+ pump. Semin. Nephrol., v.25, p. 282-291, 2005.

MARTIN, D. W. Structure-function relationships in the Na+, K+-pump. In: Seminars in nephrology. WB Saunders, v. 25, p. 282-291, 2005.

MCDONALD, P. R. A.et al. Animal Nutrition 7th ed. 2001, 712 p.

MCDOWELL, L. R. Minerals in Animal and Human Nutrition, London: Academic Press. 524 p, 1992.

MCDOWELL, L. R. Minerals in Animal and Human Nutrition. Amsterdam: Elsevier, 2003.

MILLS, C. F.; DAVIES, A. C. Zinc deficiency and zinc requirement of calves and lambs. British Journal of Nutrition, v. 21, p.751-768, 1979.

MOREIRA, F. B. Pastagens para ovinos. PUBVET, Londrina, v. 2, n. 10, Março, 2008.

NATIONAL RESEARCH COUNCIL - NRC. Nutrient requirements of dairy cattle. 7.ed. Washington, D.C.: National Academy Press, 381p., 2001.

NATIONAL RESEARCH COUNCIL - NRC. Nutrient requirements of small ruminants. Washington: The National Academic Press. 325 p., 2007.

OLSON, J. D. The role of selenium and vitamin $\mathrm{E}$ in mastitis and reproduction of daily cattle. IRISH VETERINARY JOURNAL, v. 49, n. 6, p. 362-364, 1996.

ORTOLANI, E. L. Macro e microelementos. SPINOSA, HS; GÓRNIAK, SL; BERNARDI, M.M. Farmacologia aplicada à Medicina Veterinária, v. 4, p. 641-651, 2002.

OUTTEN, C. E.; O'HALLORAN, T. V. Femtomolar sensitivity of metalloregulatory proteins controlling zinc homeostasis. Science, v. 292, n. 5526, p. 2488-2492, 2001. 
PEDREIRA, M. S.; BERCHIELLI, T. T. Minerais. In: BERCHIELLI, T. T.; et al. Nutrição de Ruminantes. Jaboticabal: FUNEP, 583p., 2006.

PETTY, T. W.; CECAVA, M. J. Beef cattle feeding and nutrition. Elsevier, 1995.

SILVA, N. C. D.; MARTINS, T. L. T.; BORGES, I. Efeito dos microminerais na alimentação de ruminantes. Ciência Animal, v. 27, n.1. p 75-98, 2017.

SOUTHGATE, D. A. T.; JOHNSON, I.; FENWICK, G. R. Nutrient availability: chemical and biological aspects. AFRC Institute of Food Research, Norwich ed., 1989. 404p. (Special Publication no. 72).

STULC, J. Placental transfer of Inorganic Ions and Water. Physiology Reviews, v. 77, n.3, p.805-836, 1997.

SUTTLE, N. F. Mineral Nutrition of Livestock. Cambridge: CABI International, v. I, ed. 4, 2010.

SYKES, A. R.; FIELD, A. C. Effects of dietary deficiencies of energy, protein and calcium on the pregnant ewe. I. Body composition and mineral content of the ewes. The Journal of Agricultural Science, v. 78, n. 1, p. 109-117, 1972.

TOKARNIA, C. H.; DÖBEREINER, J.; PEIXOTO, P.V. Deficiências minerais em animais de fazenda, principalmente bovinos em regime de campo. Pesquisa Veterinária Brasileira, v. 20, n. 3, p. $127-138,2000$.

UNDERWOOD, E. J. Progress and perspectives in the study of trace element metabolism in man and animals. Trace element metabolism in animals, p. 5-21, 1970.

UNDERWOOD, E .J. The mineral nutrition of livestock. London: Academic Press, 1981.

UNDERWOOD, E. J.; SUTTLE, N. F. The mineral nutrition of livestock. Cabi International. Ed. 3, 614p. 1999.

VAN SOEST, P. J. Nutritional ecology of the ruminant. Journal of Nutrition, v. 125, n. 4, p. 1025-1025, 1994.

WILSON, J. G. et al. Bovine functional infertility in Devon and Cornwall: response to manganese therapy. Veterinary Record, v. 79, p. 562-566, 1966.

YUYAMA, L. K. O.; COZZOLINO, S. M. F. Interação de zinco e vitamina A em ratos na lactação. Modelo de deficiência experimental. Archivos Latino americanos de Nutrición, Guatemala, v.45, n.4, p.305-309, 1995. 